\title{
Putting the Greater Dimensions of Obesity into Perspective
}

\author{
Johannes Hebebrand \\ Department of Child and Adolescent Psychiatry, University of Duisburg-Essen, Essen, Germany
}

Tackling a complex disorder as a physician or researcher can be frustrating if the etiology of the respective disorder is unknown and no curative treatment is available. Many modernday disorders fit into this category, obesity being one of them. Our impatience and frustration at times tend to obscure the fact that medicine is a constantly evolving field, which is clearly influenced by social and political factors. While true breakthroughs are rare, small steps forward are being taken at a daily level. In comparison to just a few decades ago we have made progress into combating both cancer and cardiovascular disorders. Lifestyle changes such as tobacco control were important in achieving these improvements as were true advancements in specific medical specialties. Clearly some of these changes were brought about by exerting pressure on specific interest groups, sometimes even supported by physicians [e.g. 1]. But just consider that over the last 50 years, the survival rates for childhood cancer have risen from $10 \%$ to almost $80 \%$ [2].

These advances typically apply to post-industrial countries. The health care systems of developing countries are not capable of providing complex and expensive treatments that are usually accessible in developed countries. Furthermore, despite substantial reductions in smoking rates in affluent countries, recent global estimates nevertheless place the mortality burden from tobacco use at over 6 million annually, with nearly two thirds of these deaths occurring in developing countries [3]. Even within affluent countries it is not only obesity that occurs more frequently in the less privileged. Instead many different somatic and mental disorders occur more commonly in individuals of a lower socioeconomic background. The focus on obesity obscures the dire truth that health and life expectancy depend on education and earnings. The fact that social inequality starts exerting its effects prenatally [4] all the more underscores this problem. We must be careful to not misuse obesity to point to the relationship between social status and health. Obviously, medicine and biology by themselves provide no remedy; the problem is a long-standing one, which indeed requires input from many different fields.
In this context, obesity has only recently entered the picture; it should additionally be noted that in the USA socioeconomic disparities in overweight have changed over time, with an overall trend of weakening [5]. The causal evidence underlying the statement that obesity is the negative side of success and prosperity in our modern Western world is thus limited [6]. And yes, it indeed can be argued that inequality represents a huge challenge for the scientific community. But I would also argue that we already have a good idea of what could be done to reduce the impact of the effect of socioeconomic factors on health. It seems that both politicians and voters for whatever reasons shun away from these issues. Improvements of prenatal and postnatal environments of disadvantaged children obviously require vast financial resources.

Obesity-related research has begun to take off in the 1990s as a result of the growing awareness of the obesity epidemic. Thus, the total annual number of PubMed articles pertaining to the search term 'obesity' has increased more than ten-fold from 1980 and 2009 (table 1); obesity articles started to increase relatively between 1990 and 1995. Between 1990 and 2009 the relative increase was approximately equivalent to $375 \%$. In 2009 about $1.6 \%$ of all publications pertained to obesity. We have definitely grown at an impressive level, but we nevertheless need to be well aware of the fact that increased research efforts just began a mere 20 years ago. Compare this relative recent upsurge with the much longer research tradition for cardiovascular disorders or cancer! Thus, 118,340 publications in 2009 are picked up using the search term cancer, which is equivalent to almost $14 \%$ of all publications.

We have made substantial progress in the elucidation of peripheral and central pathways involved in body weight regulation. These past two decades have taught us that mutations in single genes can cause extreme obesity. We now know that overexpression or knockdowns of many different genes affect body weight in rodent models. Genome-wide association studies have taught us that polygenic variants are difficult to detect and have small effect sizes and that those currently

\section{KARGER}

Fax +497614520714

Information@Karger.de

www.karger.com
(C) 2010 S. Karger GmbH, Freiburg

Accessible online at:

www.karger.com/ofa
Prof. Dr. Johannes Hebebrand

Department of Child and Adolescent Psychiatry

University of Duisburg-Essen

Virchowstraße 174, 45147 Essen, Germany

Tel: +49 201 7227-465, Fax -302

johannes.hebebrand@uni-due.de 
Table 1. Total number of annual publications listed in PubMed (www.ncbi. nlm.nih.gov/pubmed), annual number of publications for the search term 'obesity'

and percentage of total publications pertaining to the search term obesity from 1980 to 2009

\begin{tabular}{llllllll}
\hline \multicolumn{3}{c}{ Year } & & & & \\
\cline { 2 - 7 } & 1980 & 1985 & 1990 & 1995 & 2000 & 2005 & 2009 \\
\hline Total number of publications & 277,818 & 331,330 & 405,255 & 440,323 & 527,138 & 693,425 & 852,822 \\
Obesity & 1,227 & 1,327 & 1,696 & 2,268 & 3,823 & 8,300 \\
\% of total publications & 0.44 & 0.40 & 0.42 & 0.51 & 0.73 & 1.20 & 1.57 \\
\hline
\end{tabular}

known explain only a small proportion of the total BMI variance [7]. Bariatric surgery was proven to be effective, and we have evidence that it reduces mortality [8]. Only a few pharmacological compounds have made it up to a phase III study; currently orlistat is the only compound that can officially be prescribed for weight reduction in Europe.

How do we ourselves judge this progress? In his editorial Manfred J. Müller [9] suggests to broaden our focus as a consequence of too few relevant results. I totally agree that, as in every other field of science, it is important to be open-minded. For instance, just recently Klimentidis et al. [10] described an increase in mean body weight in many different mammalian species over the last decades, pointing to as yet sparsely researched explanations for the obesity epidemic. It should be noted that the prevalence rates for human obesity have seemingly begun to plateau in different countries [11]. The reasons underlying this recent leveling off are currently not understood; the trend started prior to the recent financial crisis. Such a plateau has for instance also been noted in German children and adults [12], despite for instance liberalization of opening times of stores and supermarkets. Whereas shops had to close at 6:30 pm just a few years ago, it is now common for supermarkets to be open until 9 or $10 \mathrm{pm}$, implying that food and drinks can now be purchased during the evening hours.

Based on what evidence does obesity really have to become a hot topic of civil society organizations? If the goal is to reduce stigmatization of obese individuals, I would totally agree. If obesity is used to criticize our current way of life and our political establishment, I would not be willing to readily agree. As pointed out above, other health problems show a stronger relationship to social inequality; we definitely need more research to elucidate how social inequality affects health and how we can curtail the negative effects of a low socioeconomic background. I would also argue that we need to get as many researchers as possible from different fields to work on obesity and to come up with solutions as to how to better tackle the epidemic via both therapeutic and preventive measures including structural changes. For this endeavor, a biologist and physician are as welcome as a sociologist or a lawyer. We all need to pay attention to the fact that obesity does not result from a single cause and that the underlying causes may differ substantially inter-individually. Our open-mindedness will prevent us from becoming nerds; nevertheless everyone is asked to do their best in their respective research field. Our personal interest in obesity is driven by the multiplicity of the issues at hand. And I personally do not care who comes up with a solution (most likely 'only' applicable to a subgroup of obese individuals); I do not require that any of the potentially very many solutions 'address the causes or the cause of the causes of obesity' as long as they work and their positive effects clearly outweigh their adverse effects.

\section{References}

1 Alderman J: Ethical implications of physician involvement in lawsuits on behalf of the tobacco industry. J Law Med Ethics 2007;35:692-698, 513.

2 O'Leary M, Krailo M, Anderson JR, Reaman GH; Children's Oncology Group: Progress in childhood cancer: 50 years of research collaboration, a report from the Children's Oncology Group. Semin Oncol 2008;35:484-493.

> Wipfli H, Samet JM: Global economic and health benefits of tobacco control: part 1. Clin Pharmacol Ther 2009;86:263-271.

4 Conroy K, Sandel M, Zuckerman B: Poverty grown up: how childhood socioeconomic status impacts adult health. J Dev Behav Pediatr 2010; 31:154-160.

5 Wang Y, Zhang Q: Are American children and adolescents of low socioeconomic status at increased risk of obesity? Changes in the association between overweight and family income between 1971 and 2002. Am J Clin Nutr 2006;84:707-716.
6 Egger G, Swinburn B: Planet Obesity - How We Are Eating Ourselves and the Planet to Death. Crows Nest, Allan and Unwin, 2010.

7 Hebebrand J, Volckmar AL, Knoll N, Hinney A: Chipping away the 'missing heritability': GIANT steps forward in the molecular elucidation of obesity - but still lots to go. Obes Facts 2010;3(5):294-303.

8 Sjöström L, Narbro K, Sjöström CD, Karason K, Larsson B, Wedel H, Lystig T, Sullivan M, Bouchard C, Carlsson B, Bengtsson C, Dahlgren S, Gummesson A, Jacobson P, Karlsson J, Lindroos AK, Lönroth H, Näslund I, Olbers T, Stenlöf K, Torgerson J, Agren G, Carlsson LM; Swedish Obese Subjects Study: Effects of bariatric surgery on mortality in Swedish obese subjects. N Engl J Med 2007;357:741-752.
9 Müller JM: The greater dimension of obesity. Obes Facts 2010;3(6):339-340.

10 Klimentidis YC, Beasley TM, Lin H-Y, Murati G, Glass GE, Guyton M, Newton W, Jorgensen M, Heymsfield SB, Kemnitz J, Fairbanks L, Allison DB: Canaries in the coal mine: a cross-species analysis of the plurality of obesity epidemics. Proc R Soc B;2010: doi:10.1098/rspb.2010.1890.

11 Rokholm B, Baker JL, Sørensen TI: The levelling off of the obesity epidemic since the year 1999 - a review of evidence and perspectives. Obes Rev 2010;doi: 10-1111/j.1467-789X.2010-00810.x.

12 Hebebrand J: Irrtum Übergewicht. Munich, Zabert Sandmann, 2008. 